\title{
Risk for Coerced Sex Among Female Youth in Ghana: Roles of Family Context, School Enrollment And Relationship Experience
}

By Jeffrey $B$. Bingenheimer and Elizabeth Reed

Jeffrey $B$.

Bingenheimer is assistant professor,

Department of

Prevention and Community Health, Milken Institute for Public Health, George Washington University,

Washington, DC. Elizabeth Reed is assistant professor, Division of Global Public Health, School of Medicine, University of California at San Diego, USA.
CONTEXT: A better understanding is needed of the variables that may influence the risk of experiencing coerced sex among adolescent females in Sub-Saharan Africa.

METHODS: Data were collected from 700 female respondents who were interviewed in 2010 and 2012 waves of a longitudinal study of behavioral risk for HIV infection among youth aged 13-14 or 18-19 and living in two towns in southeastern Ghana. A series of logistic regression models examined the influences of household composition and wealth, four family process variables (behavioral control, relationship quality, financial support, conflict), school enrollment and relationship experience on females'risk of experiencing coerced sex.

RESULTS: Eighteen percent of respondents reported having experienced coerced sex prior to Wave 1, and 13\% experienced it between Waves 1 and 2. In both cross-sectional and prospective models, the variable with the strongest association with having experienced coerced sex was having ever had a boyfriend (fully adjusted odds ratios, 4.5 and 2.6, respectively). In cross-sectional analyses, parental behavioral control was negatively associated with risk for coerced sex, while parental conflict was positively associated; these associations were not significant in the prospective analyses. Having a boyfriend appears to be the primary predictor of coerced sex among young females, beyond any influence of family, school or other household variables.

CONCLUSIONS: More research is needed to understand the context of females'relationships with boyfriends in an effort to reduce the risk of sexual coercion and to promote the prevention of sexual violence perpetrated by males within these relationships.

International Perspectives on Sexual and Reproductive Health, 2014, 40(4):184-195, doi: 10.1363/4018414
High rates of sexual coercion and sexual violence against adolescent females have been consistently reported in Ghana and elsewhere in Sub-Saharan Africa. ${ }^{1-4}$ Sexual victimization has been recognized as a violation of human rights, as well as a major threat to the health and wellbeing of females, and adverse physical, sexual, behavioral and mental health consequences have been reported in studies around the world. ${ }^{5,6}$ Among the most notable and well-documented consequences of sexual victimization are the effects on adolescents' reproductive and sexual health, including unplanned pregnancy, poor pregnancy outcomes (e.g., stillbirth, miscarriage, low birth weight), and STIs and HIV infection. , $^{3,7-11}$ A public health focus on adolescent females is particularly important, given their high rates of victimization and because such experiences have been found to have long-lasting negative impacts on their passage into adulthood (e.g., via unintended pregnancies, HIV infection, psychosocial effects and influences on health behaviors). 5,6,12

Efforts to address sexual victimization require improved understanding of the factors driving male perpetration, as well as identification of the aspects of females' lives (e.g., relationship, school, family) that may be associated with victimization. ${ }^{13,14}$ Social norms that promote gender inequities (e.g., male dominance) have been consistently found to be associated with male perpetration of violence against girls and women, ${ }^{15-23}$ and thus contexts in which such inequities are promoted are likely to have higher levels of victimization. In contrast, social contexts in which there is equal investment in girls and boys may reduce females' vulnerability to sexual victimization. In such contexts, other factors may be present that help prevent victimization, such as increased monitoring. ${ }^{13,14}$ Altogether, these findings highlight the need for a contextual-level approach to address sexual coercion, including the recognition that gender-specific characteristics may contribute to the perpetration of sexual violence against young women.

One primary risk factor for experiencing sexual coercion is being in an intimate relationship. ${ }^{14,24}$ Previous research suggests that most coerced sex is not perpetrated by strangers but by persons who are known to the victim, and particularly by partners in intimate relationships. ${ }^{5,6}$ Much research has therefore focused on characteristics such as age, socioeconomic and power differentials between partners associated with an elevated risk of coerced sex in intimate relationships. ${ }^{25,26}$ Comparatively little research, however, has examined whether simply being (versus not being) in a romantic relationship is a proximate risk factor for coerced sex. Furthermore, many studies of correlates of sexual victimization restricted their analytic samples to adolescent 
females who had reported a history of sexual activity. 3,4,27 Yet sexually inexperienced females are also at risk of coerced sex, and excluding them from studies may result in misleading conclusions. One study, for example, found that being in school was associated with coerced first sex among adolescent females in Malawi. ${ }^{2}$ Because the analysis excluded sexually inexperienced females, however, this association could in fact be attributable to in-school females being at lower risk than out-of-school females for consensual first sex rather than at higher risk for coerced first sex.

A substantial body of literature suggests that, in SubSaharan Africa, school enrollment is a powerful impediment to the formation of intimate partnerships. While enrollment may increase the opportunity to meet males and form relationships, multiple studies have shown that enrolled females are much less likely than those not enrolled to have sex and to be in romantic relationships. ${ }^{28-30}$ Many studies suggest that females who are enrolled in school may be exposed to social norms that discourage the development of sexual and romantic relationships, ${ }^{29,30}$ and that these norms may also support investment in females, hence decreasing their vulnerability to victimization. However, while various studies have examined the influence of school enrollment on females' sexual behaviors and initiation, less research has assessed the relationship between enrollment and vulnerability to sexual victimization specifically, particularly in Sub-Saharan Africa. ${ }^{12,31}$

In addition to school enrollment and relationship status, numerous family structure and process variables may lead to an increase in females' risk for, or provide some protection against, coerced sex. These may operate directly or through enrollment or relationship experience. One of the most investigated family processes is behavioral control, which includes monitoring of youth by parents or other family adults, as well as the presence of household rules and the consistency with which those rules are enforced. Parental monitoring and behavioral control have been shown to be negatively associated with the likelihood of sexual activity among U.S. adolescents. ${ }^{32-39}$ Other studies have found that monitoring by parents and other family adults is associated with a reduced risk of sexual activity among youth in Ghana and elsewhere in Sub-Saharan Africa. ${ }^{40-44}$ Regarding the risk of coerced sex, monitoring or behavioral control more broadly could operate in two ways. First, females who are more closely monitored may be less likely than others to get involved in romantic relationships. Second, even when they do get involved, behavioral control could limit male partners' opportunities to coerce them into having sex.

The closeness and quality of the parent-youth relationship have also been associated with adolescent sexual activity in numerous studies in the United States, ${ }^{45-49}$ and similar findings have been reported in studies of youth in Sub-Saharan Africa. ${ }^{50,51}$ Conversely, several U.S. studies ${ }^{46,52,53}$ have shown that conflict with parents is associated with sexual activity and involvement in romantic relationships. These associations may reflect processes in which females who have lower-quality relationships with their parents or family adults, and who experience more conflict with these individuals, are more likely to form romantic and sexual relationships with young men as a means of getting emotional support and validation that they do not receive from their families. Being in those relationships, in turn, may place female youth at risk for coerced sex.

One family characteristic that has not been widely studied in the United States, but that may be particularly relevant in Sub-Saharan Africa, is financial support. Numerous studies suggest that, in many parts of Sub-Saharan Africa, adolescent and young adult females often enter into romantic and sexual relationships in hopes of receiving financial support from their partners. ${ }^{26,54-57}$ This increases the likelihood of forming such relationships with older men, thereby increasing the risk of experiencing coerced sex. Age differences (male partners who provide financial support are often older), together with the desire for economic return, likely increase females' vulnerability to victimization, particularly if financial support creates sexual obligations.

Family processes in turn may be linked to characteristics such as household composition and wealth. Households in which both biological parents are present may be better able to monitor youth and provide emotional and financial support. ${ }^{58-60}$ Conversely, although the evidence is inconsistent, ${ }^{61,62}$ some data indicate that youth who are fostered out to extended family (a common practice throughout Africa ${ }^{63}$ ) may experience lower levels of behavioral control, relationship quality and financial support, and may experience more conflict with household adults, than youth who reside with biological parents, resulting in lower levels of well-being. ${ }^{64,65}$ Other evidence, however, suggests that the effects of child fosterage may be more complex and may depend on the specifics of the fostering arrangement and the circumstances surrounding it. ${ }^{62}$ For example, families that have fewer financial resources may be less able to provide financial support to their youth or to keep them in school. Thus, household composition and wealth may influence family processes, the likelihood of school enrollment and the initiation of relationships with male partners, and these factors likely intersect in contributing to females' risk for coerced sex.

More research is needed to understand the processes that may link family context, school status and relationship experience to risk for coerced sex. Thus, our objectives are the development and testing of a conceptual model that focuses on relationship status, school enrollment and family processes in relation to adolescent females' risk for sexual victimization (Figure 1, page 186).

\section{METHODS \\ Setting and Data Collection}

The data come from Waves 1 and 2 of a longitudinal cohort study in two towns in southeastern Ghana. Both are market towns along a major road connecting Ghana's 
FIGURE 1. Conceptual model for influences of family context, school enrollment and relationship status on young women's risk of coerced sex

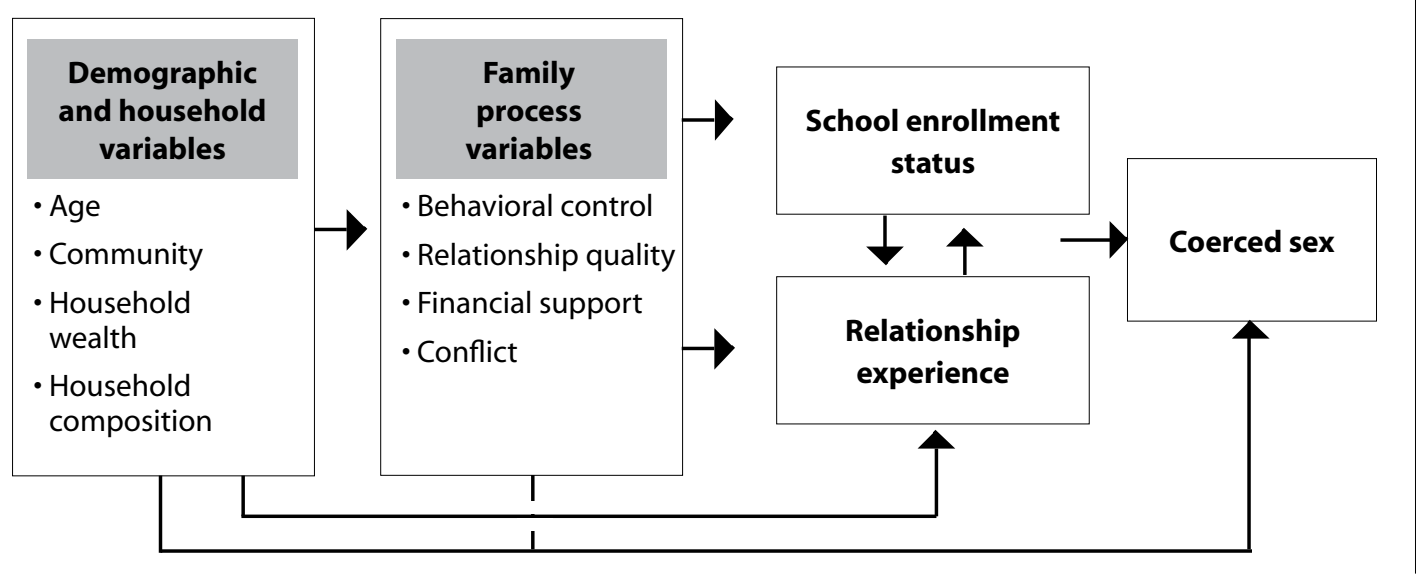

capital, Accra, with that of the Volta region. Each has a population of around 15,000. The towns differ, however, in the prevalence of HIV. Although Ghana as a whole has a relatively low HIV prevalence of $1.4 \%$ among adults aged $15-49,{ }^{66}$ one of the study communities (the town of Agormanya, Lower Manya Krobo District, Eastern Region) has suffered a severe localized HIV epidemic believed to have been driven at least in part by the circular migration of young women from this community to Abidjan, the capital of neighboring Cote d'Ivoire, during the 1980s and early 1990s. ${ }^{67-69}$ The most recent sentinel surveillance data estimate that the HIV prevalence among pregnant women attending an antenatal clinic in this area is $10.4 \% .^{70}$ The other study community (Juapong) is $40 \mathrm{~km}$ away in a district (Central Tongu, Volta Region) where 2012 sentinel surveillance data estimate the HIV prevalence among pregnant women at $2.8 \%$. $^{70}$

In the summer of 2010, field teams visited every dwelling structure and enumerated all unmarried youth aged 13-14 (the younger cohort) or 18-19 (the older cohort) living in these towns. The younger cohort was intended mainly for prospective analyses of the transition to first sex, while the older one was intended primarily for analyses of outcomes such as family formation and multiple partnerships, which are more common among older youth. The resulting sampling frame contained 1,823 names. We drew a simple random sample of 1,714 youth from this list. Of these, nine were ineligible owing to age or marital status; 430 could not be relocated, declined to participate or were of unknown disposition; and 1,275 agreed to participate and were interviewed, yielding a response rate of $75 \%$.

Twenty months later, field teams conducted Wave 2 interviews with 1,206 of the original participants, for a follow-up rate of $95 \%$. Wave 1 and 2 interviews each lasted approximately two hours and covered a range of topics, only some of which figure in the current analyses. Moreover, the current study focuses on female respondents, of whom there were 700 at Wave 1. The protocol was approved by institutional review boards at George Wash- ington University and the Noguchi Memorial Institute for Medical Research at the University of Ghana.

\section{Measures}

We focused on two dependent variables: coerced sex prior to Wave 1 and reported at that interview, and coerced sex during the period between waves and reported in the Wave 2 interview. We analyzed both of these variables because they have different advantages and disadvantages with respect to inference. The main advantage of the second variable is the clear temporal and, therefore, potentially causal ordering. In examining associations between independent variables measured at Wave 1 and outcomes occurring later, there is little reason for concern about reverse causation (although other sources of spuriousness are possible). However, fewer instances of coerced sex were reported between waves than prior to Wave 1 , and we may therefore have more statistical power to detect cross-sectional associations than prospective ones. Moreover, an implicit assumption of the prospective analysis is that independent variables measured at Wave 1 accurately characterize respondents' circumstances during the period between waves. To the extent that this is not true-that is, that the independent variables change over time-Wave 1 measures will function as imperfect proxies for circumstances between waves. Because this is a source of possible downward bias in associations measured prospectively, we therefore analyzed both versions of the dependent variable and based our conclusions on both sets of results.

The variable of coerced sex prior to Wave 1 was assessed as follows. Partway through the Wave 1 interviews, respondents were asked if they had ever had sexual intercourse. Those responding affirmatively were then asked, "The first time you had sex, would you say that you wanted to have sex, it just happened, you were pressured into doing it, or you were forced to do it?" Any respondent who indicated that her first experience of sexual intercourse was either "pressured" or "forced" was categorized as having experienced coerced sex. Later in the interview, and regardless 
of how they had answered earlier questions, respondents were asked, "Has anyone ever physically forced you to have sex with them?" and "Has anyone ever used the threat of force to get you to have sex with them?" Any respondent who answered either of these questions affirmatively was also counted as having been coerced into sex prior to her Wave 1 interview.

Our measure of coerced sex between waves drew upon similar items. At Wave 2, respondents were again asked about the nature of their first sexual experience, and whether anyone had ever used force or the threat of force to get them to have sex. The same algorithm as in Wave 1 was used to categorize each respondent as either ever or never having experienced coerced sex prior to the Wave 2 interview. Respondents who said they had never experienced coerced sex were categorized as not having experienced coerced sex between waves. Those who had reported no experience of sexual coercion in their Wave 1 interviews, but who reported experiencing coerced sex at Wave 2, were categorized as having experienced coerced sex between waves. For those who reported having experienced coerced sex at both waves, two additional items were used to determine whether any of their experiences had occurred between surveys: "Did that happen before or after our first interview with you a year and a half ago?" and "Have there been any times between our first interview with you and today when someone has used force or the threat of force to get you to have sex with them?" Respondents who answered "after" to the first question or "yes" to the second were categorized as having experienced coerced sex between waves.

Because the interviews at both waves included multiple questions about experiencing coerced sex, we were able to perform some consistency checks. At each wave, the vast majority of respondents provided logically consistent responses to the questions about coercion at first sex and any experience of coerced sex. However, in Wave 1 and 2 interviews, 25 and 37 respondents, respectively, described their first experience of sexual intercourse as "physically forced" or "pressured," but subsequently responded negatively to the questions, "Has anyone ever physically forced you to have sex with them?" and "Has anyone ever used the threat of force to get you to have sex with them?" This apparent inconsistency may be attributable in part to the different thresholds between coerced and not coerced implied by these interview questions and their response options. Specifically, respondents may have characterized their first sexual experience as "pressured" but then responded negatively to the questions about ever experiencing force or the threat of force. Indeed, this appears to account for 55 of the 62 seemingly contradictory responses. In addition, although the vast majority of respondents provided logically consistent responses across waves, some did not: Fifty-five respondents who indicated some experience of coerced sex during their Wave 1 interview reported never having experienced coerced sex during their Wave 2 interview. It is unclear what accounts for these inconsisten- cies, but possible explanations include cognitive reframing of earlier events, respondents being less comfortable discussing sensitive events during Wave 2 than they were during Wave 1, respondents misunderstanding questions and interviewers miscoding responses. For analytic purposes, we treated these 55 respondents as having experienced coerced sex prior to Wave 1 (i.e., cross-sectional analyses), and as not having experienced any additional coerced sex between Waves 1 and 2 (prospective analyses).

Following our conceptual model, the independent variables were grouped into four blocks, and all were assessed at the Wave 1 interview. The first block consists of demographic and household variables. Community of residence was either Agormanya (the town with high HIV prevalence) or Juapong (the one with low prevalence). For respondents who reported a month and year of birth, age was calculated using that information; for those who were unable or unwilling to report a month and year of birth, age was based on their answer to the question, "How old are you now?" The household composition variable was determined by household roster data in which respondents reported the name, age, gender and relation for each member of their household. We originally sorted respondents into six categories: living with both biological parents, living with the biological mother but not the father, living with the biological father but not the mother, living with extended family adults (i.e., aunts, uncles, stepmothers, stepfathers, grandmothers, grandfathers) but neither biological parent, living with no family adult and a residual "other" category. Because of the small number of respondents residing with their biological father but not their mother, we combined that group with those living with their biological mother but not their father to form a larger group of respondents who were living with one biological parent. Our measure of household wealth is similar to that used in the Demographic and Health Surveys. ${ }^{71}$ Respondents were asked whether their household (or anyone in their household) had each of the following: electricity, radio, television, mobile phone, refrigerator, flush toilet, working motorcycle or scooter, and working car or truck. Responses were coded 0 for "no" and 1 for "yes." They were also asked to indicate whether, compared with others in their area, their household was "poorer than most" (coded 0), "fairly typical in terms of wealth" (coded 0.5 ) or "wealthier than most" (coded 1). These nine indicators had a Cronbach's alpha of 0.73 . We computed their mean as our measure of household wealth.

Our second block comprises four independent variables, all measures of family processes assessed at the Wave 1 interview. They were developed from preexisting instruments, ${ }^{72-75}$ and their psychometric properties have been described elsewhere. ${ }^{51}$ The behavioral control scale consists of six items (e.g., "There is an adult in your life who knows where you are at night") and has a Cronbach's alpha of 0.73 . The relationship quality scale consists of nine items (e.g., "There is an adult in your life who listens to you") and has a Cronbach's alpha of 0.80 . The finan- 
TABLE 1. Selected characteristics of female respondents aged 13-14 or 18-19 living in two towns in southeastern Ghana, 2010

$\begin{array}{ll}\text { Characteristic } & \begin{array}{l}\text { \% or mean } \\ (\mathrm{N}=700)\end{array} \\ \end{array}$

Town HIV prevalence

Low (Juapong) $\quad 49.1$

High (Agormanya) $\quad 50.9$

Age at Wave 1

$15.78(2.43)$

Household composition

Lives with both biological parents 25.3

Lives with one biological parent $\quad 29.9$

Lives with extended family adults only $\quad 28.9$

Lives with no family adult $\quad 15.0$

Other

1.0

Household wealth (range, 0-1)

$0.46(0.21)$

Behavioral control (range, 1-3)

Relationship quality (range, 1-3)

Financial support (range, 1-3)

Conflict (range, 1-3)

School enrollment

No

Yes

Ever had boyfriend

No

Yes

Had coerced sex before Wave 1

No

82.1

Yes

Had coerced sex between Waves 1 and 2

No

Yes

87.4

12.6

Notes: Percentages may not total 100.0 because of rounding. Figures in parentheses are standard deviations.

cial support scale includes three items (e.g., "There is an adult in your life who provides for your necessities") and has a Cronbach's alpha of 0.82. Finally, the conflict scale, with a Cronbach's alpha of 0.73 , consists of five items (e.g., "There is an adult in your life who gets mad at you a lot"). Response options for all 23 items were "very true" (coded 3), "somewhat true" (coded 2) and "not at all true" (coded 1). We computed each scale score as the mean of the component items, with values ranging from 1 to 3 .

Our third and fourth blocks each consist of a single independent variable: school enrollment status or relationship experience, respectively. Both were assessed at Wave 1. Enrollment was assessed with the question, "Are you currently attending school?" Relationship experience was assessed by asking "Have you ever had a boyfriend?" In this setting, having a boyfriend does not necessarily imply sexual contact; of the 195 females who reported having had a boyfriend, 51 (26\%) said they had never had sex.

\section{Analysis}

Our analysis consisted of four stages. First, we used multiple model-based imputation of missing values to create 10 completed data sets to reduce the loss of statistical power and the risk of bias from missing data on two variables. Of the total sample of 700 females, one was missing a response to the household wealth index, and 63 were missing responses on coerced sex between Waves 1 and 2 (mostly because of loss to follow-up). We imputed values for these using the multiple imputation technique of iteratively chained equations ${ }^{76,77}$ (employing the mi impute chained command in Stata 13). All subsequent analyses used mi estimate commands.

Next, we examined bivariate associations among the independent variables. We did this sequentially, beginning with the associations between demographic variables and household composition (Block 1) and family process variables (Block 2). We then identified associations among our four family process variables. Finally, we examined associations between family process variables and school enrollment and relationship experience (Blocks 3 and 4, respectively). For associations among continuous variables, we estimated Pearson correlation coefficients and obtained $\mathrm{p}$ values from simple linear regression models. For associations between continuous and categorical variables, we calculated subgroup means and 95\% confidence intervals, and obtained $\mathrm{p}$ values from linear regression models with dummy variables.

In the third stage of analysis, we estimated bivariate associations between each of the 10 independent variables (all four blocks) and the two dependent variables. We conducted 20 logistic regression models, one for each combination. Continuous variables were standardized so that the odds ratios represent the effect of a one-standarddeviation change in the independent variable on the likelihood of having experienced coerced sex. We handled categorical independent variables using dummy variables.

Finally, we estimated a series of multivariate logistic regression models of coerced sex following the sequence of variables in our conceptual model. For each of the dependent variables, we began with a model that included all Block 1 variables. We then added the Block 2 variables, followed singly by Block 3 and Block 4 variables. For each block, we refer to the adjusted odds ratios from the first model in which that block appears as the "total effect" of the variables in that block, because those odds ratios are adjusted for the potentially confounding influences of variables in their own block and in all prior blocks, but not for the mediating effects of variables in subsequent blocks. We refer to the adjusted odds ratios from the full model (containing all four blocks of independent variables) as "direct effects," because they are adjusted for both confounding and mediating. For each dependent variable, we present the bivariate, total and direct effects (along with 95\% confidence intervals) in a single table. Comparison of the bivariate and total effects of a given independent variable provides a sense of how much of the bivariate association is attributable to confounding by prior variables. Similarly, comparison of the direct and total effects provides a sense of the extent to which the effect of that variable is mediated by subsequent variables. 


\begin{tabular}{|c|c|c|c|c|}
\hline Characteristic & $\begin{array}{l}\text { Behavioral } \\
\text { control }\end{array}$ & $\begin{array}{l}\text { Relationship } \\
\text { quality }\end{array}$ & $\begin{array}{l}\text { Financial } \\
\text { support }\end{array}$ & Conflict \\
\hline \multicolumn{5}{|l|}{ BLOCK 1 WITH BLOCK 2 VARIABLES } \\
\hline Low (Juapong) & $2.72(2.67-2.76)^{* * *}$ & $2.84(2.81-2.86)$ & $2.85(2.82-2.89)$ & $1.35(1.31-1.40)^{* *}$ \\
\hline High (Agormanya) & $2.56(2.52-2.61)$ & $2.82(2.78-2.85)$ & $2.83(2.79-2.88)$ & $1.47(1.41-1.53)$ \\
\hline Age & $-0.34^{* *}$ & $-0.15^{* *}$ & $-0.26^{* * *}$ & $0.21^{* * *}$ \\
\hline \multicolumn{5}{|l|}{ Household composition } \\
\hline Lives with both biological parents & $2.72(2.66-2.78)^{* * * *}$ & $2.88(2.84-2.91)^{* *}$ & $2.88(2.83-2.93)^{* *}$ & $1.37(1.30-1.43)$ \\
\hline Lives with one biological parent & $2.68(2.62-2.73)$ & $2.84(2.81-2.88)$ & $2.85(2.80-2.90)$ & $1.43(1.36-1.51)$ \\
\hline Lives with extended family adults only & $2.62(2.57-2.68)$ & $2.81(2.77-2.85)$ & $2.88(2.83-2.92)$ & $1.39(1.32-1.46)$ \\
\hline Lives with no family adult & $2.47(2.36-2.58)$ & $2.75(2.68-2.81)$ & $2.70(2.59-2.81)$ & $1.50(1.39-1.61)$ \\
\hline Other & $2.64(2.33-2.96)$ & $2.62(2.30-2.94)$ & $2.86(2.66-3.05)$ & $1.31(0.97-1.66)$ \\
\hline Household wealth & $0.19 * * *$ & $0.12^{*}$ & $0.20^{* * *}$ & 0.00 \\
\hline \multicolumn{5}{|l|}{ AMONG BLOCK 2 VARIABLES } \\
\hline Behavioral control & 1.00 & & & \\
\hline Relationship quality & $0.52^{* * *}$ & 1.00 & & \\
\hline Financial support & $0.51^{* * *}$ & $0.44^{* *}$ & 1.00 & \\
\hline Conflict & $-0.17^{* * *}$ & $-0.18^{* *}$ & $-0.22^{* * *}$ & 1.00 \\
\hline \multicolumn{5}{|c|}{ BLOCK 2 VARIABLES WITH BLOCK 3 AND 4 VARIABLES } \\
\hline School enrollment & & & & \\
\hline No & $2.39(2.30-2.48)^{* * *}$ & $2.74(2.69-2.80)^{* * *}$ & $2.63(2.53-2.72)^{* * *}$ & $1.59(1.49-1.68)^{* * *}$ \\
\hline Yes & $2.72(2.69-2.75)$ & $2.85(2.83-2.87)$ & $2.91(2.89-2.93)$ & $1.36(1.32-1.40)$ \\
\hline \multicolumn{5}{|l|}{ Ever had boyfriend } \\
\hline No & $2.75(2.72-2.77)^{* * *}$ & $2.86(2.84-2.89)^{* * *}$ & $2.91(2.89-2.93)^{* * *}$ & $1.35(1.31-1.39)^{* * *}$ \\
\hline Yes & $2.37(2.29-2.45)$ & $2.73(2.68-2.78)$ & $2.67(2.58-2.75)$ & $1.58(1.50-1.66)$ \\
\hline
\end{tabular}

${ }^{*} p<.05 .{ }^{* *} p<.01 .{ }^{* * *} p<.001$. Note: Block 1 consists of demographic variables and household composition; Block 2 comprises family process variables; and Blocks 3 and 4 each consist of a single variable, school enrollment status or relationship experience, respectively.

\section{RESULTS}

Respondents were evenly distributed between the two study communities, and had a mean age of 15.8 (15.7 in Juapong vs. 15.9 in Agormanya), reflecting the fact that a greater proportion of Juapong respondents were in the younger cohort (Table 1). Overall, similar proportions of respondents were living with both biological parents, one biological parent or extended family adults (25-30\%), while only $15 \%$ were living with no family adult. The average scores on the behavioral control, relationship quality and financial support scales were skewed toward the upper ends of their ranges, whereas the average on the conflict scale was near the middle. Three-quarters of respondents were enrolled in school, and seven in 10 had never had a boyfriend. Eighteen percent reported having experienced coerced sex prior to Wave 1, and 13\% said they had been coerced between the two surveys.

Respondents living in the low-HIV-prevalence town reported a higher level of behavioral control and a lower level of conflict than did those in the high-prevalence town (Table 2). Compared with younger respondents, older respondents reported lower levels of behavioral control, relationship quality and financial support (Pearson coefficients, -0.2 to -0.3$)$, and a higher level of conflict (0.2). Household composition was associated with three of the four family process variables. In general, respondents living with one biological parent reported levels of behavioral control, relationship quality and financial support similar to those living with both biological parents. Respondents who lived with extended family adults differed only slightly on these variables from those who lived with one or both biological parents. The outlying group was those living with no family adult, who reported lower levels of behavioral control, relationship quality and financial support. Household wealth was positively associated with these three variables $(0.1-0.2)$.

Correlations among the first three family process variables were all positive and substantial (coefficients, 0.40.5 ), which suggests that these processes include distinct but interrelated aspects of a broader phenomenon of positively engaged parenting and caregiving. In contrast, conflict was negatively and somewhat weakly correlated with the other variables ( -0.2 for each). Behavioral control, relationship quality and financial support were positively associated with school enrollment and negatively associated with relationship experience, whereas these relationships with conflict were reversed.

In the bivariate analyses, age was the only Block 1 variable that was associated with having experienced coerced sex prior to Wave 1: Older respondents were more likely than younger ones to report this experience (odds ratio, 1.5-Table 3, page 190). All four family process variables were correlated with coerced sex. Higher levels of behavioral control, relationship quality and financial support 


\begin{tabular}{|c|c|c|c|}
\hline Characteristic & Bivariate & Total effect & Direct effect \\
\hline \multicolumn{4}{|l|}{ BLOCK 1} \\
\hline \multicolumn{4}{|l|}{ Town HIV prevalence } \\
\hline Low (Juapong)(ref) & 1.00 & 1.00 & 1.00 \\
\hline High (Agormanya) & $0.84(0.57-1.23)$ & $0.70(0.46-1.06)$ & $0.44(0.27-0.72)^{* *}$ \\
\hline Age & $1.45(1.33-1.59)^{* * *}$ & $1.46(1.34-1.60)^{* * *}$ & $1.16(1.03-1.31)^{*}$ \\
\hline \multicolumn{4}{|l|}{ Household composition } \\
\hline \multicolumn{4}{|l|}{ Lives with both biological } \\
\hline parents (ref) & $\begin{array}{l}1.00 \\
1.22(072-208)\end{array}$ & 1.00 & 1.00 \\
\hline \\
\hline adults only & $1.08(0.62-1.86)$ & $1.29(0.71-2.32)$ & $1.30(0.69-2.46)$ \\
\hline Lives with no family adult & $1.41(0.76-2.62)$ & $1.10(0.56-2.15)$ & $1.02(0.50-2.11)$ \\
\hline Other & $2.13(0.39-11.52)$ & $2.57(0.43-15.27)$ & $2.94(0.43-19.97)$ \\
\hline Household wealth & $0.87(0.72-1.05)$ & $0.90(0.73-1.11)$ & $0.92(0.73-1.16)$ \\
\hline \multicolumn{4}{|l|}{ BLOCK 2} \\
\hline Behavioral control & $0.62(0.52-0.74)^{* * *}$ & $0.76(0.59-0.97)^{*}$ & $0.85(0.65-1.10)$ \\
\hline Relationship quality & $0.77(0.65-0.91)^{* *}$ & $1.02(0.80-1.28)$ & $1.05(0.82-1.33)$ \\
\hline Financial support & $0.74(0.63-0.87)^{* * *}$ & $1.08(0.87-1.33)$ & $1.10(0.88-1.37)$ \\
\hline Conflict & $1.76(1.47-2.10)^{* * *}$ & $1.63(1.34-2.00)^{* * *}$ & $1.61(1.31-1.98)^{* * *}$ \\
\hline \multicolumn{4}{|l|}{ BLOCK 3} \\
\hline \multicolumn{4}{|l|}{ School enrollment } \\
\hline No (ref) & 1.00 & 1.00 & 1.00 \\
\hline Yes & $0.25(0.16-0.37)^{* * *}$ & $0.63(0.38-1.03)$ & $0.82(0.48-1.38)$ \\
\hline \multicolumn{4}{|l|}{ BLOCK 4} \\
\hline \multicolumn{4}{|l|}{ Ever had boyfriend } \\
\hline No (ref) & 1.00 & 1.00 & 1.00 \\
\hline Yes & $8.17(5.34-12.49)^{* * *}$ & $4.51(2.52-8.07)^{* * *}$ & $4.51(2.52-8.07)^{* * * *}$ \\
\hline
\end{tabular}

were associated with a reduced likelihood of having experienced coerced sex (0.6-0.8), and a higher level of conflict was associated with an increased likelihood of having experienced coerced sex (1.8). Respondents who were in school were less likely than others to report coerced sex (0.3), and those who had ever had a boyfriend were far more likely to have experienced coerced sex than those who had not (8.2).

In the analyses of total effects, the association of older age with higher odds of having experienced coerced sex was not diminished when we controlled for other Block 1 variables. The effects of family process variables, however, were substantially reduced once we controlled for Block 1 and 2 variables. The effects of behavioral control and conflict moved toward the null but remained significant, and the effects of relationship quality and financial support disappeared. The effect of school status also disappeared, while the effect of relationship experience was attenuated, but remained large and statistically significant (4.5).

Comparison of direct effects with total effects provides some insight into mediating processes. The fact that the fully adjusted odds ratio for age declined from 1.5 to 1.2 suggests that the effects of age were substantially mediated by family process variables, school enrollment and relationship experience. Similarly, the adjusted odds ratio for behavioral control moved closer to the null (from 0.8 to 0.9 ), suggesting that its effect on the odds of reporting coerced sex was largely mediated by school enrollment and relationship experience. In contrast, the adjusted odds ratio for conflict barely changed, suggesting that the effect of conflict on experiencing coerced sex was not mediated by enrollment or relationship experience.

Overall, fewer associations were found in the prospective analyses. Age retained a positive bivariate association with reporting coerced sex between the two waves (odds ratio, 1.3), and its estimated effect was barely affected by adjustment for other demographic variables and household composition (Table 4). Age's estimated effect was substantially reduced, however, when family process variables, school enrollment and relationship experience were controlled for (1.1), suggesting that the effects of age may be largely mediated by these variables. Of the family process variables, only conflict was correlated with coerced sex in the prospective analyses: A one-standard-deviation increase in conflict was associated with a $30 \%$ increase in the likelihood of experiencing coerced sex between the two surveys. However, the adjusted odds ratio for the total effect of the conflict variable was closer to the null and not significant, suggesting that the association between conflict and coerced sex may be largely spurious. School enrollment was not associated with coerced sex in any of our prospective models. Notably, relationship experience remained significant in bivariate and multivariate models. Net of the potentially confounding influences of all other independent variables, having ever had a boyfriend was associated with elevated odds of reporting an experience of coerced sex between Waves 1 and 2 (2.6).

\section{DISCUSSION}

Many aspects of our conceptual model are supported by the findings. Age and household composition were associated with family process variables in the expected ways. In turn, these latter variables were associated with school enrollment and relationship experience. Regarding selfreported experience of coerced sex, however, our findings were less clear-cut. Apart from age, the only independent variable that retained an association with coerced sex in all models and in both cross-sectional and prospective analyses was relationship experience. Females who had had a boyfriend were much more likely than others to report having experienced coerced sex. Moreover, our findings suggest that associations of family, school and socioeconomic variables with risk for sexual coercion are largely explained by the correlation between these factors and reports of having ever had a boyfriend. These findings are consistent with previous research indicating that the perpetrator of coerced sex against young women in SubSaharan Africa is most often her intimate male partner., Thus, while prior work has documented the elevated risk for sexual victimization among females who have relation- 
ships with male partners, this study is the first to highlight that simply being in a relationship with a boyfriend appears to be the only independent risk factor for sexual victimization, and is significant above and beyond the influence of family environment, school enrollment and other socioeconomic variables.

We found little evidence of a protective effect of school enrollment. Although the bivariate cross-sectional association suggests that females who are enrolled in school are less likely to experience coerced sex than their outof-school counterparts, multivariate analyses suggest that this association may be spurious. Moreover, in our prospective analysis, even the bivariate association failed to reach statistical significance, and in multivariate models the association crossed the null, becoming positive rather than negative. These findings are also new to the literature. While previous studies have assessed the relationship between school enrollment and sexual behaviors and initiation, ${ }^{28-30}$ little research has focused on the association between enrollment and females' risk for sexual victimization in Sub-Saharan Africa.

We found mixed evidence for the effects of family process variables on risk of coerced sex. In the cross-sectional data, all four of these variables showed the expected associations with coerced sex. The effects of behavioral control and conflict with family adults persisted when the Block 1 and 2 variables were added to the model. This suggests that behavioral control by family adults may reduce females' risk of coerced sex, while conflict with family adults may increase it. The effect of behavioral control, however, appears to be mediated to a large extent by school enrollment and relationship experience. Thus, the protective effect of behavioral control may operate primarily by keeping young women out of romantic relationships, which in turn appear to be a powerful proximate risk factor for coerced sex.

The results of our prospective analyses, however, provided little support for the effects of family processes on the risk of coerced sex. Only one family process variableconflict with family adults-had even a bivariate prospective association with coerced sex, and this relationship lost significance when the Block 1 and 2 variables were controlled for. This inconsistency in findings between the cross-sectional and prospective results may be because these analyses are subject to different types of bias. The cross-sectional analyses may overstate the associations between family process variables and coerced sex, which would occur in particular if "reverse causation" were present-that is, if coerced sex itself or its proximate risk factors influenced family processes. This is very plausible. Being in a romantic relationship, for example, may be the source of conflict between an adolescent female and the adults in her family. Such reverse causation cannot occur in the prospective analyses, since the exposure period for those analyses occurred after Wave 1, when family process variables were assessed. Conversely, the prospective analyses may understate the effects of family process variables on
TABLE 4. Odds ratios (and 95\% confidence intervals) from logistic regression analy-
ses identifying associations between selected characteristics and young women's ses identifying associations between select
reporting of coerced sex between waves

Characteristic

Bivariate

Total effect

Direct effect

\section{BLOCK 1}

Town HIV prevalence

Low (Juapong)(ref)

High (Agormanya)

Age

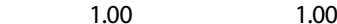

$1.06(0.67-1.70) \quad 0.99(0.61-1.62) \quad 0.87(0.53-1.47)$

$1.25(1.13-1.37)^{* * *} 1.24(1.12-1.36)^{* * *} 1.14(1.00-1.30)^{*}$

Household composition

Lives with both biological parents (ref)

Liveswith one biologic

Lives with extended family adults only

Lives with no family adult

$0.86(0.45-1.63)$

1.00

$0.78(0.40-1.51)$

$0.87(0.44-1.74)$

$1.19(0.58-2.43)$

$1.08(0.12-9.70)$

$0.78(0.40-1.53)$

Other

$1.14(0.13-9.92)$

$0.87(0.68-1.12)$

$1.29(0.62-2.69)$

Household wealth

$0.86(0.67-1.09)$

$0.83(0.64-1.09)$

BLOCK 2

Behavioral control

Relationship quality

$0.89(0.71-1.12)$

$1.05(0.77-1.43)$

$1.19(0.80-1.50)$

$1.06(0.82-1.38) \quad 1.20(0.88-1.64)$

$0.91(0.73-1.13) \quad 1.01(0.78-1.31)$

$1.23(0.90-1.68)$

Financial support

Conflict

$1.30(1.05-1.61)^{*}$

$1.22(0.97-1.54)$

$1.00(0.77-1.30)$

$1.21(0.96-1.53)$

BLOCK 3

School enrollment

No (ref)

Yes

$\begin{array}{lll}1.00 & 1.00 & 1.00\end{array}$

$0.62(0.38-1.04) \quad 1.15(0.63-2.08)$

$1.37(0.74-2.52)$

BLOCK 4

Ever had boyfriend

No (ref)

1.00

1.00

$3.25(1.99-5.30)^{* * *} 2.55(1.28-5.10)^{* *}$

1.00

$2.55(1.28-5.10)^{* *}$

${ }^{*} \mathrm{p}<.05 .{ }^{* *} \mathrm{p}<.01 .{ }^{* * *} \mathrm{p}<.001$. Notes: Block 1 consists of demographic variables and household composition; Block 2 comprises family process variables; and Blocks 3 and 4 each consist of a single variable, school enrollment status or relationship experience, respectively. Figures in the "bivariate" column are unadjusted odds ratios; those in the "total effect" column are adjusted for all variables in the same and previous blocks; and those in the "direct effect" column are adjusted for all independent variables. ref=reference group.

the risk of coerced sex, because these variables measured at Wave 1 may be imperfect proxies for females' experiences of those processes in the period between Waves 1 and 2. Therefore, further research may be needed to better understand these findings; for example, more frequent assessment of family process variables over a longer period of adolescent development could help to resolve the issue.

This study has several other limitations. The potential consequences of our use of self-reported data should be borne in mind when interpreting our results. It is widely acknowledged by investigators studying adolescent sexual and reproductive health in Sub-Saharan Africa that female youth tend to understate their actual involvement in sexual activity. ${ }^{78-82}$ Underreporting may be especially pronounced for coerced sex, since such experiences are very stigmatizing, and because these experiences are not always recognized as violence or coercion owing to societal attitudes that normalize sexual coercion against girls and women. ${ }^{83,84}$ Despite this general tendency toward underreporting of coerced sex, a significant proportion of respondents in our sample reported experiences of coerced sex that occurred before Wave 1 (18\%) or between Waves 1 and 2 (13\%). We found some logical inconsistencies in respondents' answers to questions about coerced sex, especially when comparing responses across the waves. Be- 
cause most misclassification is probably in the direction of underreporting, our prevalence and incidence estimates are probably downwardly biased. Depending on the pattern of underreporting and other misclassification, measures of association may be biased in either direction.

Another potential source of bias in this study is the omission of potential confounding variables. Although our analysis of prospective data largely eliminates the possibility of reverse causation, associations reported here could still be due to the spurious effects of omitted variables. If some participants, for example, were more comfortable than others in answering interview questions, those respondents may have been more likely to report having had a boyfriend, and more likely to acknowledge having experienced coerced sex. If so, then participants' comfort in being interviewed would be an omitted variable, and some or all of the association between relationship experience and risk of coerced sex could be attributable to its confounding influence. The possibility of such bias should be considered when interpreting our findings.

A final limitation involves our measure of relationship experience: a simple yes-or-no question asking whether the respondent had ever had a boyfriend. Those who answered affirmatively may in fact be quite heterogeneous in terms of the number of relationships experienced, and with respect to the nature of those relationships (e.g., duration, seriousness, age disparity). Presumably some types of relationships pose a greater risk than others. The fact that such a cursory measure was so strongly associated with reports of coerced sex suggests that future research using more sophisticated measures may contribute substantially to our understanding of the processes leading to coerced sex and to strategies for preventing it.

\section{Conclusions}

Our findings suggest that having ever had a boyfriend is the primary predictor of reporting coerced sex among young women, beyond any influence of family, school or other household socioeconomic variables. While family characteristics appeared to play some role, the relation between them and sexual coercion was relatively weak and largely explained by the association between family variables and having had a boyfriend. This has implications for interventions that aim to reduce Ghanaian females' risk of experiencing coerced sex. Several U.S. interventions to promote the sexual and reproductive health of youth focus on the parent-adolescent relationship by, for example, increasing parents' behavioral control skills or promoting better parent-child communication. ${ }^{85-87}$ Similar strategies are now being adapted for and evaluated in parts of SubSaharan Africa. ${ }^{88,89}$ Our findings, however, suggest that while interventions designed to increase parental behavioral control of youth, or to improve skills for managing conflict in youth-parent relationships, may have some effects on sexual behaviors, they may do little to protect adolescent females in Ghana from coerced sex.

Instead, strategies aimed at influencing behaviors with- in romantic relationships may be more promising. One approach could focus on adolescent females by teaching them that they have a right not to be coerced into sex, helping them recognize signs that a partner is likely to become coercive, and providing them with skills and resources for responding to coercive behaviors when they occur. ${ }^{90}$ Another approach could focus on boys and men by promoting more equitable gender role attitudes, by teaching them to recognize their own coercive behaviors and acknowledge them as problematic, and by encouraging them to intervene if they witness sexual coercion. ${ }^{91,92}$ Some interventions may integrate both perpetration prevention and victimization prevention strategies. ${ }^{93-95}$

The design of such interventions may benefit from additional research on the relationship contexts of coerced sex in Sub-Saharan African settings. Although our findings indicate that having ever had a boyfriend is the biggest risk factor for being coerced into sex, it is likely that some romantic relationships pose a higher risk than others. Characteristics that come into play may include age differences between partners, financial dependence of one partner on the other and the gender role attitudes of male and female partners. Beyond addressing the partner dynamics in a relationship, broader social changes may also be helpful in reducing adolescent females' risk of experiencing coerced sex. These could include the enactment of laws against sexual coercion, the strengthening of institutions for enforcing laws that already exist, and the removal of barriers to girls' and young women's access to the justice system, as well as changes in social norms not only related directly to coerced sex, but also more broadly connected to gender equity and the social acceptability of violence and coercion.

\section{REFERENCES}

1. Tenkorang EY and Owusu YA, Coerced first sexual intercourse among women in Ghana: evidence from the Demographic and Health Survey, Sexuality \& Culture, 2013, 17(1):167-184.

2. Moore AM et al., Coerced first sex among adolescent girls in subSaharan Africa: prevalence and context, African Journal of Reproductive Health, 2007, 11(3):62-82

3. Koenig MA et al., Coerced first intercourse and reproductive health among adolescent women in Rakai, Uganda, International Family Planning Perspectives, 2004, 30(4):156-163.

4. Maharaj $P$ and Munthree $C$, Coerced first sexual intercourse and selected reproductive health outcomes among young women in KwaZulu-Natal, South Africa, Journal of Biosocial Science, 2007, 39(2):231-244.

5. Garcia-Moreno C et al., Prevalence of intimate partner violence: findings from the WHO multi-country study on women's health and domestic violence, Lancet, 2006, 368(9543):1260-1269.

6. World Health Organization (WHO), World Report on Violence and Health, Geneva: WHO, 2002

7. Polis CB et al., Coerced sexual debut and lifetime abortion attempts among women in Rakai, Uganda, International Journal of Gynecology $\varepsilon$ Obstetrics, 2009, 104(2):105-109.

8. Agardh A et al., The invisible suffering: sexual coercion, interpersonal violence, and mental health-a cross-sectional study among university students in south-western Uganda, PLoS ONE, 2012, 7(12):e51424, doi:10.1371/journal.pone.0051424, accessed Apr. 9, 2014. 
9. Stockman JK, Lucea MB and Campbell JC, Forced sexual initiation, sexual intimate partner violence and HIV risk in women: a global review of the literature, AIDS and Behavior, 2013, 17(3):832-847.

10. Wagman J et al., Experiences of sexual coercion among adolescent women: qualitative findings from Rakai district, Uganda, Journal of Interpersonal Violence, 2009, 24(12):2073-2095.

11. Upchurch DM and Kusunoki Y, Associations between forced sex, sexual and protective practices, and sexually transmitted diseases among a national sample of adolescent girls, Women's Health Issues, $2004,14(3): 75-84$

12. Dartnall $E$ and Jewkes R, Sexual violence against women: the scope of the problem, Best Practice \& Research: Clinical Obstetrics \& Gynaecology, 2013, 27(1):3-13

13. Stephenson R, Community influences on young people's sexual behavior in 3 African countries, American Journal of Public Health, 2009, 99(1):102-109.

14. Blanc AK et al., A Review of the Evidence on Multi-sectoral Interventions to Reduce Violence Against Adolescent Girls, New York: Population Council, 2013

15. Anderson KL and Umberson D, Gendering violence-masculinity and power in men's accounts of domestic violence, Gender $\&$ Society, 2001, 15(3):358-380

16. Anderson VN, Simpson-Taylor D and Herrmann DJ, Gender, age, and rape-supportive rules, Sex Roles, 2004, 50(1-2):77-90

17. Goicolea I et al., Condemning violence without rejecting sexism? Exploring how young men understand intimate partner violence in Ecuador, Global Health Action, 2012, 5:1-12.

18. Murnen SK, Wright $C$ and Kaluzny G, If "boys will be boys," then girls will be victims? A meta-analytic review of the research that relates masculine ideology to sexual aggression, Sex Roles, 2002, 46(1112):359-375.

19. Palma-Solis M, Vives-Cases C and Alvarez-Dardet C, Gender progress and government expenditure as determinants of femicide, Annals of Epidemiology, 2008, 18(4):322-329.

20. Reed E et al., Male perpetration of teen dating violence: associations with neighborhood violence involvement, gender attitudes, and perceived peer and neighborhood norms, Journal of Urban Health, 2011, 88(2):226-239.

21. Reed E et al., Social and environmental contexts of adolescent and young adult male perpetrators of intimate partner violence: a qualitative study, American Journal of Men's Health, 2008, 2(3):260-271.

22. Santana MC et al., Masculine gender roles associated with increased sexual risk and intimate partner violence perpetration among young adult men, Journal of Urban Health, 2006, 83(4):575-585.

23. Zakar R, Zakar MZ and Kraemer A, Men's beliefs and attitudes toward intimate partner violence against women in Pakistan, Violence Against Women, 2013, 19(2):246-268.

24. Van Decraen E et al., Sexual coercion among in-school adolescents in Rwanda: prevalence and correlates of victimization and normative acceptance, African Journal of Reproductive Health, 2012, 16(3):140154.

25. Blanc AK, The effect of power in sexual relationships on sexual and reproductive health: an examination of the evidence, Studies in Family Planning, 2001, 32(3):189-213.

26. Luke N, Age and economic asymmetries in the sexual relationships of adolescent girls in sub-Saharan Africa, Studies in Family Planning, 2003, 34(2):67-86

27. Erulkar AS, The experience of sexual coercion among young people in Kenya, International Family Planning Perspectives, 2004, 30(4):182-189.

28. Biddlecom A et al., Associations between premarital sex and leaving school in four sub-Saharan African countries, Studies in Family Planning, 2008, 39(4):337-350

29. Glover EK et al., Sexual health experiences of adolescents in three Ghanaian towns, International Family Planning Perspectives, 2003 , 29(1):32-40.
30. Gupta N and Mahy M, Adolescent childbearing in subSaharan Africa: Can increased schooling alone raise ages at first birth? Demographic Research, 2003, 8(4):93-106.

31. Young AM, Grey M and Boyd CJ, Adolescents' experiences of sexual assault by peers: prevalence and nature of victimization occurring within and outside of school, Journal of Youth and Adolescence, 2009, 38(8):1072-1083

32. DiClemente RJ et al., Parental monitoring: association with adolescents' risk behaviors, Pediatrics, 2001, 107(6):1363-1368

33. Longmore MA, Manning WD and Giordano PC, Preadolescent parenting strategies and teens' dating and sexual initiation: a longitudinal analysis, Journal of Marriage and Family, 2001, 63(2):322-335.

34. Miller BC, Benson B and Galbraith KA, Family relationships and adolescent pregnancy risk: a research synthesis, Developmental Review, 2001, 21(1):1-38

35. Miller KS, Forehand R and Kotchick BA, Adolescent sexual behavior in two ethnic minority groups: a multisystem perspective, Adolescence, 2000, 35(138):313-333.

36. Rose A et al., The influence of primary caregivers on the sexual behavior of early adolescents, Journal of Adolescent Health, 2005, 37(2):135-144.

37. Sieverding JA et al., The influence of parental monitoring on adolescent sexual initiation, Archives of Pediatrics \& Adolescent Medicine, 2005, 159(8):724-729.

38. Stanton BF et al., Parental underestimates of adolescent risk behavior: a randomized, controlled trial of a parental monitoring intervention, Journal of Adolescent Health, 2000, 26(1):18-26.

39. Yang $\mathrm{H}$ et al., Dynamic association between parental monitoring and communication and adolescent risk involvement among AfricanAmerican adolescents, Journal of the National Medical Association, 2007, 99(5):517-524

40. Babalola S, Tambashe BO and Vondrasek C, Parental factors and sexual risk-taking among young people in Côte d'Ivoire, African Journal of Reproductive Health, 2005, 9(1):49-65.

41. Biddlecom A, Awusabo-Asare K and Bankole A, Role of parents in adolescent sexual activity and contraceptive use in four African countries, International Perspectives on Sexual and Reproductive Health, 2009 , 35(2):72-81.

42. Kumi-Kyereme A et al., Influence of social connectedness, communication and monitoring on adolescent sexual activity in Ghana, African Journal of Reproductive Health, 2007, 11(3):133-149.

43. Puffer ES et al., Individual- and family-level psychosocial correlates of HIV risk behavior among youth in rural Kenya, AIDS and Behavior, 2011, 15(6):1264-1274.

44. Wamoyi J et al., Parental control and monitoring of young people's sexual behaviour in rural north-western Tanzania: implications for sexual and reproductive health interventions, BMC Public Health, 2011, 11:106, doi:10.1186/1471-2458-11-106, accessed Apr. 9, 2014

45. Davis EC and Friel LV, Adolescent sexuality: disentangling the effects of family structure and family context, Journal of Marriage and Family, 2001, 63(3):669-681.

46. McBride CK, Paikoff RL and Holmbeck GN, Individual and familial influences on the onset of sexual intercourse among urban African American adolescents, Journal of Consulting and Clinical Psychology, 2003, 71(1):159-167.

47. Ream GL and Savin-Williams RC, Reciprocal associations between adolescent sexual activity and quality of youth-parent interactions, Journal of Family Psychology, 2005, 19(2):171-179.

48. Resnick MD et al., Protecting adolescents from harm, Journal of the American Medical Association, 1997, 278(10):823-832.

49. Sieving RE, McNeely CS and Blum RW, Maternal expectations, mother-child connectedness, and adolescent sexual debut, Archives of Pediatrics \& Adolescent Medicine, 2000, 154(8):809-816

50. Dimbuene ZT and Defo BK, Risky sexual behaviour among unmarried young people in Cameroon: another look at family environment, Journal of Biosocial Science, 2011, 43(2):129-153. 
51. Bingenheimer JB, Asante E and Ahiadeke C, Reliability, validity, and associations with sexual behavior among Ghanaian teenagers of scales measuring four dimensions of relationships with parents and other adults, Journal of Family Issues, 2013, doi:10.1177/0192513X13497349, accessed Oct. 1, 2014

52. Black MM, Ricardo IB and Stanton B, Social and psychological factors associated with AIDS risk behaviors among low-income, urban, African American adolescents, Journal of Research on Adolescence, 1997 7(2):173-195

53. Dowdy BB and Kliewer W, Dating, parent-adolescent conflict, and behavioral autonomy, Journal of Youth and Adolescence, 1998, 27(4):473-492.

54. Jewkes R and Morrell R, Sexuality and the limits of agency among South African teenage women: theorising femininities and their connections to HIV risk practices, Social Science \& Medicine, 2012, 74(11):1729-1737

55. Luke N, Confronting the "sugar daddy" stereotype: age and economic asymmetries and risky sexual behavior in urban Kenya, International Family Planning Perspectives, 2005, 31(1):6-14.

56. Silberschmidt $M$ and Rasch V, Adolescent girls, illegal abortions and "sugar-daddies" in Dar es Salaam: vulnerable victims and active social agents, Social Science E Medicine, 2001, 52(12):1815-1826.

57. Wamoyi J et al., Transactional sex amongst young people in rura northern Tanzania: an ethnography of young women's motivations and negotiation, Reproductive Health, 2010, 7:2, doi:10.1186/1742 4755-7-2, accessed Feb. 12, 2014

58. Barrett AE and Turner RJ, Family structure and mental health: the mediating effects of socioeconomic status, family process, and social stress, Journal of Health and Social Behavior, 2005, 46(2):156-169.

59. Demo DH and Acock AC, Family structure, family process, and adolescent well-being, Journal of Research on Adolescence, 1996, 6(4):457488

60. Dimbuene ZT and Defo BK, Family environment and premarital intercourse in Bandjoun (West Cameroon), Archives of Sexual Behavior, 2012, 41(2):351-361.

61. Hampshire K et al., Context matters: fostering, orphanhood, and schooling in sub-Saharan Africa, Journal of Biosocial Science, 2014, doi:10.1017/S0021932014000169, accessed Sept. 3, 2014.

62. Rwenge M, Sexual risk behaviors among young people in Bamenda, Cameroon, International Family Planning Perspectives, 2000, 26(3):118-123 \& 130.

63. Isiugo-Abanihe UC, Child fosterage in West-Africa, Population and Development Review, 1985, 11(1):53-73.

64. Agblorti SKM and Tanle A, Child fostering and education in Ghana Social Biology \& Human Affairs, 2011, 76(1):53-70.

65. Morantz G et al., Child abuse and neglect among orphaned children and youth living in extended families in sub-Saharan Africa: What have we learned from qualitative inquiry? Vulnerable Children and Youth Studies, 2013, 8(4):338-352.

66. Joint United Nations Programme on HIV/AIDS (UNAIDS), Global Report: UNAIDS Report on the Global AIDS Epidemic 2013, Geneva: UNAIDS, 2013

67. Agyei-Mensah S, Twelve years of HIV/AIDS in Ghana: puzzles of interpretation, Canadian Journal of African Studies, 2001, 35(3):441-472.

68. Decosas J, HIV and development, AIDS, 1996, 10(Suppl. 3):S69$\mathrm{S} 74$.

69. Anarfi JK, Sexual networking in selected communities in Ghana and the sexual behaviour of Ghanaian female migrants in Abidjan, Cote d'Ivoire, in: Dyson T, ed., Sexual Behaviour and Networking: Anthropological and Sociocultural Studies on the Transmission of HIV Liège, Belgium: International Union for the Scientific Study of Population, 1992, pp. 223-247.

70. National AIDS/STI Control Programme (NACP), Ghana Health Service and Ministry of Health, National HIV Prevalence and AIDS Estimates Report, 2012-2016, Accra, Ghana: NACP, 2013.

71. Rutstein SO and Johnson K, The DHS wealth index, DHS
Comparative Reports, Calverton, MD, USA: ORC Macro, 2004, No. 6.

72. Armsden GC and Greenberg MT, The inventory of parent and peer attachment: individual differences and their relationship to psychological well-being in adolescence, Journal of Youth and Adolescence, 1987 16(5):427-454.

73. Brown BB et al., Parenting practices and peer group affiliation in adolescence, Child Development, 1993, 64(2):467-482.

74. Furman W and Buhrmester D, The network of relationships inventory: behavioral systems version, International Journal of Behavioral Development, 2009, 33(5):470-478.

75. McQuestion $\mathrm{M}$ et al., Psychosocial processes and sexual initiation among Ghanaian youth, Health Education \& Behavior, 2012 39(3):268-275

76. White IR, Royston P and Wood AM, Multiple imputation using chained equations: issues and guidance for practice, Statistics in Medicine, 2011, 30(4):377-399.

77. Royston P, Multiple imputation of missing values, Stata Journal, 2004, 4(3):227-241

78. Aral SO and Peterman TA, Measuring outcomes of behavioural interventions for STD/HIV prevention, International Journal of STD E AIDS, 1996, 7(Suppl. 2):30-38

79. Fishbein $\mathrm{M}$ and Pequegnat W, Evaluating AIDS prevention interventions using behavioral and biological outcome measures, Sexually Transmitted Diseases, 2000, 27(2):101-110.

80. Mensch BS, Hewett PC and Erulkar AS, The reporting of sensitive behavior by adolescents: a methodological experiment in Kenya, Demography, 2003, 40(2):247-268.

81. Nnko S et al., Secretive females or swaggering males? An assessment of the quality of sexual partnership reporting in rural Tanzania Social Science \& Medicine, 2004, 59(2):299-310.

82. Plummer ML et al., "A bit more truthful": the validity of adolescent sexual behaviour data collected in rural northern Tanzania using five methods, Sexually Transmitted Infections, 2004, 80(Suppl. 2):ii49-ii56.

83. Botta RA and Pingree S, Interpersonal communication and rape: women acknowledge their assaults, Journal of Health Communication, 1997, 2(3):197-212

84. Fisher BS et al., Acknowledging sexual victimization as rape: results from a national-level study, Justice Quarterly, 2003, 20(3):535-574

85. Blake SM et al., Effects of a parent-child communications intervention on young adolescents' risk for early onset of sexual intercourse, Family Planning Perspectives, 2001, 33(2):52-61.

86. Lederman RP, Chan W and Roberts-Gray C, Parent-Adolescen Relationship Education (PARE): program delivery to reduce risks for adolescent pregnancy and STDs, Behavioral Medicine, 2008, 33(4):137-144.

87. Miller KS et al., Enhancing HIV communication between parents and children: efficacy of the Parents Matter! Program, AIDS Education and Prevention, 2011, 23(6):550-563.

88. Poulsen MN et al., Cultural adaptation of a U.S. evidence-based par enting intervention for rural Western Kenya: from Parents Matter! to Families Matter! AIDS Education and Prevention, 2010, 22(4):273-285.

89. Vandenhoudt $\mathrm{H}$ et al., Evaluation of a U.S. evidence-based par enting intervention in rural Western Kenya: from Parents Matter! to Families Matter! AIDS Education and Prevention, 2010, 22(4):328-343.

90. Langhinrichsen-Rohling J and Turner LA, The efficacy of an intimate partner violence prevention program with high-risk adolescent girls: a preliminary test, Prevention Science, 2012, 13(4):384-394.

91. Coker AL et al., Evaluation of Green Dot: an active bystander intervention to reduce sexual violence on college campuses, Violence Against Women, 2011, 17(6):777-796.

92. Foubert JD and Marriott KA, Effects of a sexual assault peer education program on men's belief in rape myths, Sex Roles, 1997, 36(3/4):259-268

93. Foshee VA et al., Assessing the long-term effects of the Safe Dates program and a booster in preventing and reducing adolescent dating 
violence victimization and perpetration, American Journal of Public Health, 2004, 94(4):619-624.

94. Taylor BG et al., Shifting Boundaries: an experimental evaluation of a dating violence prevention program in middle schools, Prevention Science, 2013, 14(1):64-76.

95. Wolfe DA et al., A school-based program to prevent adolescent dating violence: a cluster randomized trial, Archives of Pediatrics $E$ Adolescent Medicine, 2009, 163(8):692-699.

\section{RESUMEN}

Contexto: Se necesita comprender mejor las variables que pueden influir en el riesgo de experimentar relaciones sexuales bajo coerción en mujeres adolescentes en África subsahariana. Métodos: Se recolectaron datos de 700 mujeres que fueron entrevistadas en las olas de 2010 y 2012 de un estudio longitudinal del riesgo conductual relacionado con la infección por VIH en jóvenes de entre 13 y 14 años o entre 18 y 19 años que vivían en dos poblaciones en el sudeste de Ghana. Una serie de modelos de regresión logística examinaron cómo la composición y riqueza de los hogares, cuatro variables de procesos familiares (control conductual, calidad de las relaciones, apoyo financiero y conflicto), la inscripción en la escuela y la experiencia en las relaciones influyen en el riesgo de que las mujeres experimenten sexo bajo coerción.

Resultados: Dieciocho por ciento de las personas entrevistadas reportaron haber experimentado relaciones sexuales bajo coerción antes de la Ola 1, y 13\% las experimentaron entre las Olas 1 y 2. Tanto en los modelos de sección cruzada como en los prospectivos, la variable que presentó la asociación más fuerte con el hecho de haber experimentado sexo bajo coerción fue haber tenido alguna vez un novio (razones de probabilidades totalmente ajustadas de 4.5 y 2.6 respectivamente). En los análisis de sección cruzada, el control parental de la conducta se asoció negativamente con el riesgo de experimentar sexo bajo coerción, mientras que el conflicto con los padres se asoció de forma positiva; estas asociaciones no fueron significativas en los análisis prospectivos. El hecho de tener un novio parece ser el principal factor de predicción del sexo bajo coerción en mujeres jóvenes, más allá de cualquier influencia familiar, de la escuela o de otras variables del hogar.

Conclusiones: Se necesitan realizar más investigaciones con el fin de comprender el contexto de las relaciones de las mujeres con sus novios en un esfuerzo para reducir el riesgo de coerción sexual y promover la prevención de la violencia sexual perpetrada por los hombres dentro de estas relaciones.

\section{RÉSUMÉ}

Contexte: Il serait utile de mieux comprendre les variables d'influence du risque de rapports sexuels forcés parmi les adolescentes d'Afrique subsaharienne.

Méthodes: Les données proviennent de 700 répondantes interviewées lors des vagues 2010 et 2012 d'une étude longitudinale du risque comportemental de contraction du VIH parmi les jeunes filles de 13-14 ou 18-19 ans vivant dans deux villes du sud-est du Ghana. Différents modèles de régression logistique ont permis l'examen de l'influence de la composition et richesse du ménage, de quatre variables de traitement familiales (contrôle comportemental, qualité de la relation, soutien financier, conflit), de la scolarisation et de l'expérience relationnelle sur le risque féminin de rapports sexuels forcés.

Résultats: Dix-huit pour cent des répondantes ont déclaré avoir subi des rapports sexuels forcés avant la vague 1, et 13\% entre les vagues 1 et 2 . Dans les modèles transversaux comme prospectifs, la variable présentant la plus forte association avec le vécu de rapports sexuels forcés est celle d'avoir jamais eu un petit ami (rapport de probabilité totalement ajusté, 4,5 et 2,6, respectivement). Dans les analyses transversales, le contrôle comportemental des parents est associé négativement au risque de rapports forcés, tandis que le conflit parental l'est positivement. Ces associations ne sont pas significatives dans les analyses prospectives. Le fait d'avoir eu un petit ami semble le principal prédicteur de rapports sexuels forcés parmi les jeunes filles, au-delà de toute influence de variables familiales, de scolarisation ou autres variables de ménage.

Conclusions: Une recherche approfondie permettrait de mieux cerner le contexte des relations des jeunes filles avec leurs petits amis, en vue de réduire le risque de contrainte sexuelle et de favoriser la prévention de la violence sexuelle masculine au sein de ces relations.

\section{Acknowledgments}

The authors gratefully acknowledge funding from the Eunice Kennedy Shriver National Institute for Child Health and Human Development (R01HD061017), as well as research assistance from Tiffany Gray. The findings and conclusions of this paper are those of the authors and do not necessarily represent the official position of the National Institutes of Health.

Author contact: bartbing@gwu.edu 